\title{
The pathogenetic mechanisms of cough in idiopathic pulmonary fibrosis
}

\author{
Elena Bargagli ${ }^{1}$ (D) Maria Di Masi ${ }^{2} \cdot$ Marco Perruzza $^{1} \cdot$ Lucia Vietri $^{1} \cdot$ Laura Bergantini $^{1}$ - Elena Torricelli ${ }^{2}$. \\ Giulia Biadene $^{2} \cdot$ Giovanni Fontana $^{2} \cdot$ Federico Lavorini $^{2}$
}

Received: 14 August 2018 / Accepted: 24 September 2018

(c) Società Italiana di Medicina Interna 2018

\begin{abstract}
Idiopathic pulmonary fibrosis is a peripheral subpleural interstitial lung disorder limited to the lung not involving the airways. It has a poor prognosis (survival less than 5 years) and commonly an interstitial pneumonia radiological pattern. Patients complain of a chronic dry cough in $80 \%$ of cases. A cough is often the first symptom of this rare disease, preceding dyspnea by years, and is associated with a poor prognosis, high dyspnea scores and low FVC percentages. The pathogenetic mechanisms leading to coughing in IPF are unclear. This review focuses on recent evidence of cough pathophysiology in this disease. Gastroesophageal reflux may promote coughing in IPF patients; bile salts and pepsin may be abundant in BAL of these patients, inducing overproduction of TGF- $\beta$ by airway epithelial cells and mesenchymal transition with fibroblast recruitment/activation and extracellular matrix deposition. Patients have an enhanced cough reflex to capsaicin and substance $\mathrm{P}$ with respect to control subjects. Moreover, patients with the MUC5B polymorphism show more severe coughing as MUC5B encodes for the dominant mucin in the honeycomb cysts of IPF patients. Comorbidities, including asthma, gastroesophageal reflux, hypersensitivity pneumonitis, bronchiectasis, chronic obstructive pulmonary disease and emphysema, can induce coughing in IPF patients. There is no clear explanation of the causes of coughing in IPF. Further research into the pathophysiology of IPF and the pathogenetic mechanisms of coughing is necessary to improve survival and quality of life.
\end{abstract}

Keywords Idiopathic pulmonary fibrosis $\cdot$ Cough $\cdot$ Pathogenesis

$\begin{array}{ll}\text { Abbreviations } \\ \text { IPF } & \text { Idiopathic pulmonary fibrosis } \\ \text { ILD } & \text { Interstitial lung diseases } \\ \text { HRCT } & \text { High resolution computed tomography } \\ \text { BAL } & \text { Bronchoalveolar lavage } \\ \text { GER } & \text { Gatroesophageal reflux } \\ \text { NSIP } & \text { Non specific interstitial pneumonia } \\ \text { FVC } & \text { Forced vital capacity } \\ \text { TGF- } \beta & \text { Tumour growth factor } \\ \text { UIP } & \text { Usual interstitial pneumonia } \\ \text { GPCR } & \text { G-Protein coupled receptor }\end{array}$

Elena Bargagli

bargagli2@gmail.com

1 Section of Respiratory Diseases and Lung Transplantation, Department of Clinical Medicine and Neurosciences, Siena University Hospital, Siena, Italy

2 Section of Respiratory Medicine, Department of Clinical and Experimental Medicine, University of Florence, Florence, Italy

\section{Introduction}

Idiopathic pulmonary fibrosis (IPF) is an interstitial lung disorder limited to the lung and associated with poor prognosis (mean survival less than 5 years) and commonly an interstitial pneumonia (UIP) radiological pattern. Late diagnosis of IPF is common because the signs and symptoms of this disease are nonspecific. Eighty percent of patients complain of a chronic dry cough, but the prevalence of coughing in IPF has not been clearly established due to different definitions and assessment methods [1]. Coughing is often the first symptom of this interstitial lung disease, preceding dyspnea by years [2-5]. It is an independent marker of disease severity, being associated with a poor prognosis, high dyspnea scores, low FVC percentages, and high rates of exertion desaturation [1]. Coughing is more common in IPF patients who have never smoked than in smokers [50]. All ages and both genders are equally affected. The cough is dry, severe, diurnal, induced, for example, by speaking (favoured by vibration or mechanical stimulation of nerve receptors) and refractory to pharmacological therapies $[1,5]$. It can affect quality of life by limiting exercise tolerance and determining 
social health problems [4-7]. Coughing related to IPF may be associated with coughing induced by comorbidities such as asthma, gastroesophageal reflux (GER) disease, upper airway cough syndrome and medications [5].

New approved therapies for IPF have only been partially assessed for coughing, although there is growing interest in the topic. There is no specific approved therapy for coughing in IPF. Only one trial with thalidomide in a limited population of IPF patients with refractory coughing has been published [8]. Our research group recently conducted a randomised, double blind, placebo-controlled trial on the effectiveness of aerosolised carcainium chloride (VRP700) in controlling coughing in patients with interstitial lung diseases (ILD) [9]. Nebulised VRP700 therapy improves cough and quality of life in hospitalised ILD patients, and is without any significant side effects. In a multicentre trial, Birring et al. recently evaluate the efficacy of a new formulation of inhaled sodium cromoglycate in the treatment of chronic coughing in IPF patients [10].

There is no clear explanation of the causes of coughing in IPF patients, especially those never exposed to cigarette smoking. The pathogenetic mechanisms of coughing in IPF are unclear. Here we review recent evidence concerning the pathophysiology of coughing in this disease.

\section{Gastroesophageal reflux}

Bile salts and pepsin may be abundant in bronchoalveolar lavage (BAL) fluid from IPF patients, inducing overproduction of TGF- $\beta$ by airway epithelial cells and mesenchymal transition with fibroblast recruitment/activation and extracellular matrix deposition [11-14]. The development of IPF seems to be facilitated by recurrent lung insult due to microaspiration of Helicobacter pylori from gastric juice as a consequence of GER [14-18]. Gastroesophageal reflux (GER) is common in IPF patients, while in the general population, the prevalence of GER disease exceeds that of IPF and only a small proportion of subjects with GER develops IPF [11]. Non-acid reflux seems to influence coughing in IPF more than acid reflux. Pharmacological therapy with pump inhibitors does not improve cough symptoms. Therapy with proton pump inhibitors is able to increase non-acid reflux [11], and some interesting research articles suggest that the most apt strategy to treat gastroesophageal reflux in patients with IPF should target acid and non-acid reflux [4]. Prokinetic therapies, rather than acid suppression therapy alone, may be proposed as relevant potential targets of treatment [4].

In IPF, the cough itself may promote GER through an increase in trans-diaphragm pressure; concomitant pulmonary fibrosis causes traction of neighbouring structures, weakening the lower esophageal sphincter and aggravating gastric reflux $[4,18]$. The surgical approach to GER in IPF patients does not yield a significant improvement in cough symptoms [19, 20]. Controversial findings have been reported on the potential role of GER in IPF pathogenesis. Some authors fail to confirm the increased pepsin concentrations reported in BAL and exhaled breath condensate from IPF patients, suggesting that these findings may not be reproducible [19]. Some research groups find higher DLCO percentages in patients with IPF and GER than in those with no reflux [15].

\section{Architectural distortion of the lungs}

In obstructive lung disorders, coughing is generally due to airway involvement, but since IPF is not an airway disease, the reason for coughing in this peripheral ILD is unclear [21]. Idiopathic pulmonary fibrosis causes architectural distortion and traction bronchiectasis; mechanical forces activate rapidly adapting receptors in small airways, stimulating coughing $[22,23]$.

The airway traction occurring in IPF may promote the development of a cough, particularly in the advanced phase of the disease. There is progressive loss of alveolar integrity, recruitment/activation of myofibroblasts and excessive collagen deposition damage parenchymal architecture, causing airway distortion [22, 23].

Lung fibrosis can destroy the nerves involved in cough inhibition, facilitating the symptom. In 2011, Jones et al. demonstrated that percussive stimuli to the respiratory tract induce coughing in IPF patients, but not in controls, and that the cough increases when the base of the lungs (where IPF arises) is stimulated. Transmission of vibration caused by talking, or even coughing itself, may increase mechanical stimulation of sensory receptors, perpetuating the vicious circle of IPF and coughing [22].

\section{Increased cough reflex sensitivity}

Idiopathic pulmonary fibrosis patients have an enhanced cough reflex response to capsaicin and substance $\mathrm{P}$ with respect to controls, irrespective of the entity of fibrosis and GER [24]. The urge to cough, induced by inhalation of capsaicin, activates many areas of the cerebral cortex, especially in IPF patients (Fig. 1). Stimulation of chemical cough receptors may be related to subclinical inflammation. Eosinophils and other inflammatory markers have been found elevated in BAL fluid of IPF patients [25-28]. These mediators may modulate the cough reflex by increasing the presence of $\mathrm{G}$ protein coupled receptor (GPCR) and substance $\mathrm{P}$ in human airway nerves. C-fibre sensory nerves seem to be involved in cough development, and it is possible to reduce the dry cough associated with IPF by reducing 
Fig. 1 Pathogenetic mechanisms of cough in idiopathic pulmonary fibrosis (IPF)

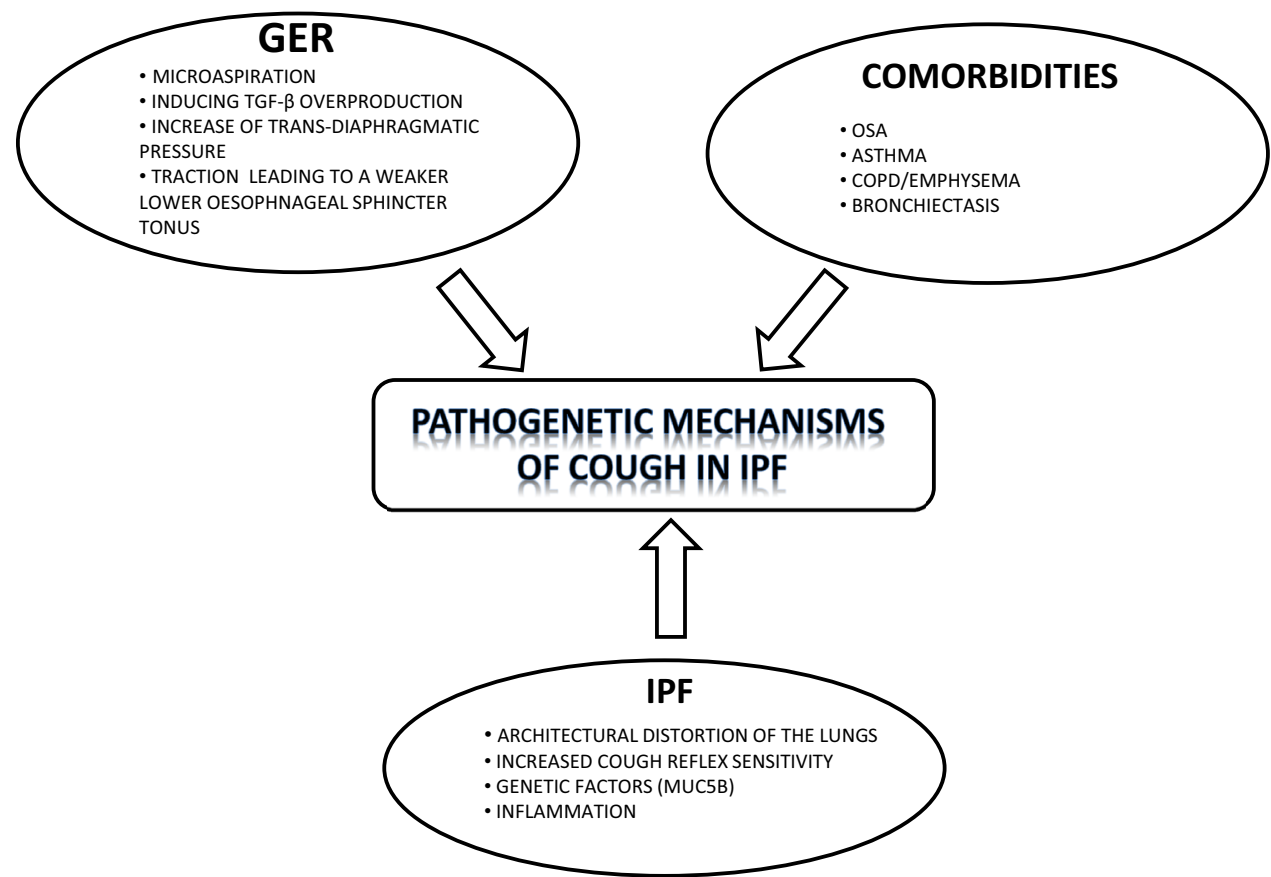

C-fibre nerve activity through a specific receptor [30-34, 50].

Neurotrophins may be generated in the lungs of IPF patients from bronchial and alveolar epithelial cells, mesenchymal cells, lymphocytes and macrophages [29, 35]. Neurotrophins regulate different subgroups of sensory neurons, increasing capsaicin sensitivity. Interestingly, immunoblots have revealed neurotrophin overexpression in patients with an UIP, but not a NSIP radiological pattern, although possible differences between cough impact in IPF and NSIP have never been evaluated [36]. Substance P-like immunoreactive material has been found overexpressed in BAL and sputum from IPF patients with respect to healthy individuals, modulating nerve proliferation and neuroplasticity. Neuropeptides, substance $\mathrm{P}$ and neurokinin A can stimulate human lung fibroblast proliferation and chemotaxis that regulate the cough reflex [36].

\section{Genetic factors}

Cough is an independent predictor of disease progression. It is more severe in IPF patients with MUC5B polymorphism [37]. MUC5B encodes an airway mucin that is the dominant mucin in the honeycomb cysts of IPF patients [38]. Changes in mucin production and clearance aggravate the cough [39-41]. Although IPF is commonly associated with a dry cough, some patients have a chesty productive cough from onset of the disease. In a recent study, the histology of autopsy lungs of IPF patients was compared in relation to wet and dry cough [42]. IPF patients with hypersecretion show mucus gland hypertrophy, accumulation of mucus in the airways and mucus hypersecretion [42].

\section{Inflammation}

An elevated percentage of polymorphonuclear cells and mast cells producing an abundance of cytokines and chemokines have been demonstrated in BAL fluid of IPF patients [27, 28]. Among the inflammatory cells overexpressed in BAL and sputum of IPF patients, eosinophils and mast cells are involved in fibrosis and cough development. These cells have been isolated near fibroblastic foci, and produce histamine, tryptase, serotonin and substance $\mathrm{P}$ that activate sensory nerve $\mathrm{C}$ fibres, promoting coughing [30, 31].

\section{Comorbidities}

Many years ago, Madison et al. reported that coughing can be an expression of different concomitant diseases in more than 50\% of IPF patients [5]. In particular, the authors suggest that comorbidities that induce coughing in these patients include: obstructive sleep apnea (OSA) syndrome, asthma, GER, hypersensitivity pneumonitis, bronchiectasis, chronic obstructive pulmonary disease and emphysema [5].

Sleep apnea is a possible comorbidity in patients with IPF, and its treatment can improve gastroesophageal reflux, chronic cough and fibrotic lung damage [43, 44] (Table 1). In fact, it has been demonstrated that the intermittent hypoxemia of patients with OSA may promote profibrotic 
Table 1 Comorbidities associated with Cough in IPF

\begin{tabular}{ll}
\hline IPF comorbidities & Mechanisms of cough \\
\hline OSAS & Profibrotic hypoxaemia \\
GER & Non-acid reflux, increase TGF- $\beta$ \\
BRONCHIECTASIS & C-fibre nerve activity \\
COPD & Hypersecretion mucous glandular \\
ASTHMA & Bronchial hyperactivity \\
\hline
\end{tabular}

mechanisms, and that obstruction of the upper airways typical of OSA syndrome may increase trans-diaphragm pressure differences, promoting GER and coughing (Fig. 1) [43-46].

\section{The potential role of airway basal cells}

Another intriguing aspect is the potential role of airway basal cells in IPF pathogenesis and cough development. Chilosi and coauthors report an aberrant bronchiolization in IPF lung with $\triangle$ NP63 expressing cells [47, 48]. IPF animal models reveal that airway basal cells may have a potential role in the early response to fibrosis, and bronchoalveolar subpopulations of ABCs are abundantly present in fibrotic lesions [49]. Migration and proliferation of a CK $5 / 6+\Delta \mathrm{NP} 63+$ progenitor cell population is an early and key event in the evolution of pulmonary fibrosis [47]. IPF is characterized by fibroblast foci, honeycomb cyst formation and bronchiolization of the alveolar space [47]. In the current model of disease pathogenesis, the bronchiolization and honeycomb cysts formation occur after the formation of myofibroblast foci. ABCs are recruited potentially in response to alveolar epithelial cell injury, and their proliferation and invasion determine the distortion of the alveolar structure that we typically associate with IPF and cough [47-50]. A very recent genetic manuscript reports an unexpected finding: genes from $\mathrm{ABCs}$ are highly enriched in the BAL of IPF patients likely to progress, and may suggest an unexpected role of ABCs in the pathogenesis of IPF and cough [49]. It was demonstrated for the first time that IPF might be regarded as a fibrotic lung disease involving and originating by the airways basal cells [49].

\section{Conclusion}

There is no clear explanation of the possible causes of coughing in IPF, a peripheral subpleural disorder not involving the airways. Further research into the pathophysiology of IPF and the pathogenetic mechanisms of coughing is necessary to improve survival and quality of life of patients.
Funding The study was unfunded.

\section{Compliance with ethical standards}

Conflict of interest The authors have no conflicts of interest related to this topic.

Statement of human and animal rights All procedures were in accordance with the ethical standard of the institutional and/or national research committee and with the 1964 Helsinki declaration and its later amendments or comparable ethical standards. This article does not contain any studies with animals performed by any of the authors.

Informed consent Informed consent was obtained from all individual participants included in the study.

\section{References}

1. Ryerson CJ, Abbritti M, Ley B et al (2011) Cough predicts prognosis in idiopathic pulmonary fibrosis. Respirology 16(6):969-975

2. Hope-Gill BDM, Hilldrup S, Davies C et al (2003) A study of the cough reflex in idiopathic pulmonary fibrosis. Am J Respir Crit Care Med 168:995-1002

3. Vigeland CL, Hughes AH, Horton MR et al (2017) Etiology and treatment of cough in idiopathic pulmonary fibrosis. Respir Med 123:98-104

4. Kilduff CE, Counter MJ, Thomas GA et al (2014) Effect of acid suppression therapy on gastroesophageal reflux and cough in idiopathic pulmonary fibrosis: an intervention study. Cough 10:4

5. Madison JM, Irwin RS (2005) Chronic cough in adults with interstitial lung disease. Curr Opin Pulm Med 11(5):412-416

6. Key AL, Holt K, Hamilton A et al (2010) Objective cough frequency in idiopathic pulmonary fibrosis. Cough 6:4

7. Sumner H, Woodcock A, Kolsum U et al (2013) Predictors of objective cough frequency in chronic obstructive pulmonary disease. Am J Respir Crit Care Med 187:943-949

8. Horton MR, Santopietro V, Mathew L et al (2012) Thalidomide for the treatment of cough in idiopathic pulmonary fibrosis: a randomized trial. Ann Intern Med 157:398-406

9. Lavorini F, Spina D, Walker MJ et al (2016) Antitussive effect of carcainium chloride in patients with chronic cough and idiopathic interstitial pneumonias: a pilot study. Pulm Pharmacol Ther 40:91-94

10. Birring SS, Wijsenbeek MS, Agrawal S et al (2017) A novel formulation of inhaled sodium cromoglycate (PA101) in idiopathic pulmonary fibrosis and chronic cough: a randomised, double-blind, proof-of-concept, phase 2 trial. Lancet Respir Med 5(10):806-815

11. Fahim A, Dettmar PW, Morice AH et al (2011) Gastroesophageal reflux and idiopathic pulmonary fibrosis: a prospective study. Medicina (Kaunas) 47(4):200-205

12. Lee JS, Song JW, Wolters PJ et al (2012) Bronchoalveolar lavage pepsin in acute exacerbation of idiopathic pulmonary fibrosis. Eur Respir J 39(2):352-358

13. Raghu G, Yang ST, Spada C, Hayes J et al (2006) Treatment of acid gastroesophageal reflux in idiopathic pulmonary fibrosis: a case series. Chest 129(3):794-800

14. Lee JS, Ryu JH, Elicker BM et al (2011) Gastroesophageal reflux therapy is associated with longer survival in patients with idiopathic pulmonary fibrosis. Am J Respir Crit Care Med 184(12):1390-1394 
15. Lee JS, Collard HR, Anstrom KJ et al (2013) Anti-acid treatment and disease progression in idiopathic pulmonary fibrosis: an analysis of data from three randomised controlled trials. Lancet Respir Med 1(5):369-376

16. Pillai M, Olson AL, Huie TJ et al (2012) Obstructive sleep apnea does not promote esophageal reflux in fibrosing interstitial lung disease. Respir Med 106:1033-1039

17. Lee JS, Collard HR, Raghu G et al (2010) Does chronic microaspiration cause idiopathic pulmonary fibrosis? Am J Med 123:304-311

18. Ing AJ, Ngu MC, Breslin AB (1994) Pathogenesis of chronic persistent cough associated with gastroesophageal reflux. Am J Respir Crit Care Med 149:160-167

19. Hoppo T, Jarido V, Pennathur A et al (2011) Antireflux surgery preserves lung function in patients with gastroesophageal reflux disease and end-stage lung disease before and after lung transplantation. Arch Surg 146(9):1041-1047

20. Linden PA, Gilbert RJ, Yeap BY et al (2006) Laparoscopic fundoplication in patients with end-stage lung disease awaiting transplantation. J Thorac Cardiovasc Surg 131(2):438-446

21. Harrison NK (2004) Idiopathic pulmonary fibrosis: a nervous cough? Pulm Pharmacol Ther 17:347-350

22. Jones RM, Hilldrup S, Hope-Gill BD et al (2011) Mechanical induction of cough in idiopathic pulmonary fibrosis. Cough 7:2

23. Harrison NK (2013) Cough, sarcoidosis and idiopathic pulmonary fibrosis: raw nerves and bad vibrations. Cough 9:9

24. Doherty MJ, Mister R, Pearson MG et al (2000) Capsaicin induced cough in cryptogenic fibrosing alveolitis. Thorax 55:1028-1032

25. Mazzone SB, McLennan L, McGovern AE et al (2007) Representation of capsaicin-evoked urge-to-cough in the human brain using functional magnetic resonance imaging. Am J Respir Crit Care Med 176:327-332

26. Alexis NE, Hu SC, Zeman K et al (2001) Induced sputum derives from the central airways: confirmation using a radiolabelled aerosol bolus delivery technique. Am J Respir Crit Care Med 164:1964-1970

27. Birring SS, Parker D, McKenna S et al (2005) Sputum eosinophilia in idiopathic pulmonary fibrosis. Inflamm Res 54:51-56

28. Kinder BW, Brown KK, Schwarz MI et al (2008) Baseline BAL neutrophilia predicts early mortality in idiopathic pulmonary fibrosis. Chest 133:226-232

29. Ricci A, Felici L, Mariotta S et al (2004) Neurotrophin and neurotrophin receptor protein expression in the human lung. Am J Respir Cell Mol Biol 30:12-19

30. Donnerer J, Schuligoi R, Stein C (1992) Increased content and transport of substance $\mathrm{P}$ and calcitonin gene-related peptide in sensory nerves innervating inflamed tissue: evidence for a regulatory function of nerve growth factor in-vivo. Neuroscience 49:693-698

31. Braun A, Lommatzsch M, Mannsfeldt A et al (1999) Cellular sources of enhanced brain-derived neurotrophic factor production in a mouse model of allergic inflammation. Am J Respir Cell Mol Biol 21:537-546

32. Yao L, Zhang D, Bernd P (1997) Differential regulation of substance $\mathrm{P}$ by all members of the nerve growth factor family of neurotrophins in avian dorsal root ganglia throughout development. Neuroscience 79:1197-1206
33. Undem BJ, Hunter DD, Liu M et al (1999) Allergen-induced sensory neuroplasticity in airways. Int Arch Allergy Immunol 118:150-153

34. Koltzenburg M (1999) The changing sensitivity in the life of the nociceptor. Pain 6:S93-S102

35. Ricci A, Graziano P, Bronzetti E et al (2007) Increased pulmonary neurotrophin protein expression in idiopathic interstitial pneumonias. Sarcoidosis Vasc Diffuse Lung Dis 24:13-23

36. Harrison NK, Dawes KE, Kwon OJ et al (1995) Effects of neuropeptides on human lung fibroblast proliferation and chemotaxis in vitro. Am J Physiol 268:L278-L283

37. Scholand MB, Wolff R, Crossno PF et al (2014) Severity of cough in idiopathic pulmonary fibrosis is associated with MUC5 B genotype. Cough 10:3

38. Seibold MA, Smith RW, Urbanek C (2013) The idiopathic pulmonary fibrosis honeycomb cyst contains a mucocilary pseudostratified epithelium. PLoS one 8(3):e58658

39. Seibold MA, Wise AL, Speer MC et al (2011) A common MUC5B promoter polymorphism and pulmonary fibrosis. N Engl J Med 364(16):1503-1512

40. Zhang Y, Noth I, Garcia JG, Kaminski N (2011) A variant in the promoter of $M U C 5 B$ and idiopathic pulmonary fibrosis. N Engl J Med 364(16): 1576-1577

41. Jiang Haiming, Yejia Hu, Shang Li et al (2015) Association between MUC5B polymorphism and susceptibility and severity of idiopathic pulmonary fibrosis Int J. Clin Exp Pathol 8(11):14953-14958

42. Andoh Y, Aikawa T, Shimura S et al (1992) Morphometric analysis of airways in idiopathic pulmonary fibrosis patients with mucous hypersecretion. Am Rev Respir Dis 145(1):175-179

43. Jaimchariyatam N, Tantipornsinchai W, Desudchit T et al (2016) Association between respiratory events and nocturnal gastroesophageal reflux events in patients with coexisting obstructive sleep apnea and gastroesophageal reflux disease. Sleep Med 22:33-38

44. Mermigkis C, Bouloukaki I, Antoniou K et al (2015) Obstructive sleep apnea should be treated in patients with idiopathic pulmonary fibrosis. Sleep Breath 19:385-391

45. Jung HK, Choung RS, Talley NJ (2010) Gastroesophageal reflux disease and sleep disorders: evidence for a causal link and therapeutic implications. J Neurogastroenterol Motil 16:22-29

46. Chan KK, Ing AJ, Laks L et al (2010) Chronic cough in patients with sleep-disordered breathing. Eur Respir J 35:368-372

47. Chilosi M, Poletti V, Murer B et al (2002) Abnormal re-epithelialization and lung remodelling in Idiopathic pulmonary fibrosis: the role of deltaN-p63. Lab Invest 82(10):1335-1345

48. Caliò A, Lever V, Rossi A et al (2017) Increased frequency of bronchiolar histotypes in lung carcinomas associated with idiopathic pulmonary fibrosis. Histopathology 71(5):725-735

49. Prasse A, Binder H, Schupp JC et al. (2018) BAL cell gene expression is indicative of outcome and airway basal cell involvement in IPF. Respir Crit Care Med (in press)

50. Van Manen MJ, Birring SS, Vancheri C et al (2016) Cough in idiopathic pulmonary fibrosis. Eur Respir Rev 25(141):278-286 